\title{
VEHICLE POLLUTION CONTROL AND TRAFFIC MANAGEMENT
}

\author{
J.N.Mohite ${ }^{1}$, S.S.Barote ${ }^{2}$ \\ ${ }^{1}$ Asst professor, Department of electronics, M.S.S.C.E.T Jalna, India \\ ${ }^{2}$ Student, Department of electronics, M.S.S.C.E.T Jalna, India
}

\begin{abstract}
In developing countries the new emerging problem is pollution emission through vehicles. This problem is largely occurring in metro cities like Mumbai, Delhi and Pune etc. to control the pollution the monitoring system needs to develop. There are various projects on the pollution emission monitoring in various countries but due to the technological, economical differences of developed countries and developing countries these projects cannot be implemented in developing countries. Another aspect of system is cost, the cost of system should be low this can be achieve by using low cost components like ZIGBEE. In this paper a cost effective solution to monitor vehicle pollution and automatic traffic management is discussed. The problems regarding multi tagging, efficiency of on board device can be overcome by proposed system. This system provides traffic management without adding further cost.
\end{abstract}

Keywords: ZIGBEE, PUC, MY SQL, SIAM and vehicle pollution monitoring. *** $*$

\section{INTRODUCTION}

Now a day's number vehicles are increasing day by day. In cities like Pune, Mumbai and Delhi number of vehicles is far more. Due to incomplete combustion in the engine of a vehicle the pollution through vehicle increases. In US $27 \%$ of $\mathrm{Co}_{2}$ emission occurred through vehicles [1].as shown in pie chart.

\section{CO2 emission due to different sources}

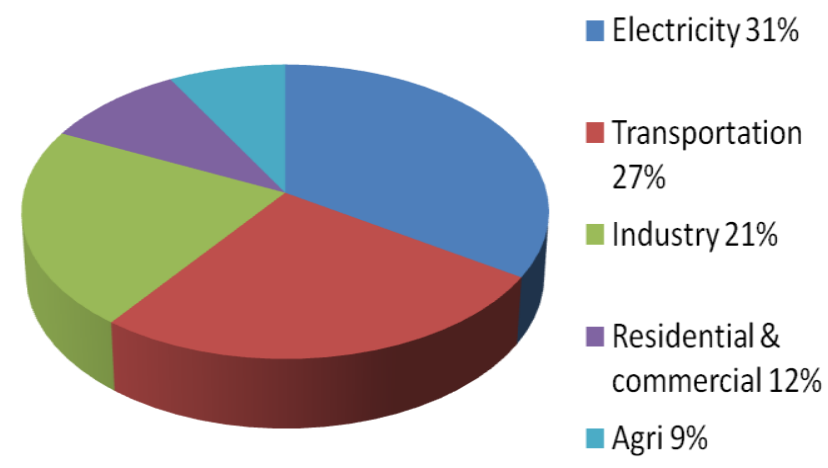

Chart-1: $\mathrm{CO}_{2}$ emission due to different sources [1].

Day by day number of vehicles are increasing tends to increase $\mathrm{CO}_{2}$. According to Mumbai pollution control board logs, pollution levels particularly $\mathrm{NO}_{\mathrm{X}}$, and SPM suspended particulate matter increased rapidly.SPM shot up to as high as $286 \mu$ gram/cubic meter and $\mathrm{NO}_{\mathrm{X}} 211 \mu \mathrm{gram} /$ cubic meter. SPM anything above $100 \mu$ gram/cubic meter and $\mathrm{NO}_{\mathrm{X}}$ $88 \mu \mathrm{gram} / \mathrm{cubic}$ meter is very bad for health. The main sources of pollution in metro cities are vehicles. The SIAM (society of Indian Automobile manufacturers) has scenario is as follows In India, the idle emission test has been introduced since mid eighties.co emission through vehicles has been tested with limit 3\%. A vehicle with improper combustion is in most cases likely to fail the idle CO test. Thus the vehicle could be advised to go to a workshop for suitable maintenance. From October 2004 HC (hydro carbon) is also measured. PUC vehicles are used to measure vehicle emission but this is very time consuming method. The system need to develop which will measure pollution through vehicles without taking time of vehicle owner. There are two ways either to use RFID or ZIGBEE [2]. The problem is regarding RFID as the range of RFID is problem. If we used high power RFID then cost increases i.e. for $100 \mathrm{~m}$ RFID cost is 15000.so cost of the system also increases. So system should be developing to reduce the cost of whole system. So instead of using RFID we will use the ZIGBEE module which reduces the cost of system and will cover more area. This report consists of five chapters. The first chapter is dedicated to introduction where objective of project is discussed. The second chapter is dedicated to literature survey. Focusing on history related to this project. Third chapter gives information to all project components and there interconnection to form the project. In fourth chapter traffic management through system is discussed. In fifth chapter advantages and disadvantages are discussed. Conclusion of this project discussed in sixth chapter.

\section{RELATED WORK}

Recently, different pollution control systems discussed in literatures. In 2014 "Application of RFID Technology and the Maximum Spanning Tree Algorithm for Solving Vehicle Emissions in Cities on Internet of Things" presented by chi-man vong in this paper a pollution control system for developed countries is discussed the system consist of RFID tag to which the lambda sensor is connected through analog to digital converter. The lambda sensor mounted on exhaust pipe to measure air ratio when air ratio is less than one carbon monoxide and hydrocarbon emission will increased and when air ratio greater than one more nitrogen oxide will 
be produced. This value is read by RFID reader. This RFID tag transfer data to another RFID unit. This module is connected to the $3 \mathrm{G}$ card through which data is send to the database server where all the data with date is available. The standards and received data from the vehicles are compared if the standards does not match with the data then message is generated and send to the vehicle owner. In this paper for mounting of the RFID tag efficiently by using maximum spanning tree algorithm is also discussed which help us to mount RFID tag on minimum traffic junctions and covers large traffic [2]. The second paper Automated System for Air Pollution Detection and Control in Vehicles presented by Anita kulkarni, T. Ravi Teja. In this paper on board pollution control system discussed. If pollution through vehicles crosses predefined standards then this system stops vehicle and message generated and sent to specific number which is stored in GSM module problem [3]. Another paper presented called etc assisted traffic light control scheme for reducing vehicles co2 emissions by chunxiao li and shigeru shimamoto. In this paper author presents a vehicle's $\mathrm{CO} 2$ emission reduction scheme by an ETC-assisted real-time traffic light control scheme in vehicular networks. Using Electronic Toll Collection (ETC) devices traffic at each junction can be find out. ETC devices communicate with signals at each junction. With the help of this communication traffic at each junction is obtained [4]. Comparison of previous system and proposed system is given in following table.

Table -1: Comparison of proposed system with previous

\begin{tabular}{|l|l|l|l|l|l|}
\hline $\begin{array}{l}\text { Sr. } \\
\text { no. }\end{array}$ & Features & $\begin{array}{l}\text { WF- } \\
\text { IOT[2] }\end{array}$ & $\begin{array}{l}\text { IJARE } \\
\text { EIE[3] }\end{array}$ & $\begin{array}{l}\text { IJMIT } \\
{[4]}\end{array}$ & $\begin{array}{l}\text { Proposed } \\
\text { system }\end{array}$ \\
\hline 1 & $\begin{array}{l}\text { Monitor } \\
\text { pollution } \\
\text { through } \\
\text { vehicles }\end{array}$ & Yes & Yes & No & Yes \\
\hline 2 & $\begin{array}{l}\text { Traffic } \\
\text { managem } \\
\text { ent }\end{array}$ & No & No & Yes & Yes \\
\hline 3 & $\begin{array}{l}\text { CO } 2 \\
\text { emission } \\
\text { reduction }\end{array}$ & No & No & yes & Yes \\
\hline 4 & cost & Low & High & High & Low \\
\hline
\end{tabular}

Bharat stage emission standard are emission standards instituted by government of India which regulate the output of air pollutants through vehicles. In India nationwide Bharat stage III standards are followed nationwide and Bharat stage IV standards are followed in metro cities.

\section{SYSTEM DEVELOPMENT}

The pollution control and traffic management system has low cost, efficient and also reduce $\mathrm{co} 2$ emission through vehicles by reducing stand by time. This system is divided into three parts.

1. On board unit(OBU)

2. Road side unit(RSU)

3. Server side unit(SSU)

\subsection{On Board Unit (OBU)}

Fig 1 shows on board unit. The on board unit consist of sensors, ADC, microcontroller and ZIGBEE module. In this unit the $\mathrm{CO}, \mathrm{NO}, \mathrm{SO}$ sensor is used to collect the data of pollution due to the vehicle. This data fed to ADC analog to digital converter which converts all analog data to digital data. This digital data afterwards fed to microcontroller. Microcontroller in each vehicle contains specific identity number. Data along with identity number transfer to the ZIGBEE module. Then it transmits towards road side unit. ZIGBEE Feature Set is designed to support smaller networks with hundreds of devices in a single network. The ZIGBEE specification enhances the IEEE 802.15.4 standard by adding network and security layers and an application framework. From this foundation, Alliance developed standards, technically referred to as public application profiles, can be used to create a multi-vendor interoperable solutions. There are three categories of nodes in a ZIGBEE system. They are Coordinator, Router and End devices. Coordinator Forms the root of the network tree and might bridge to other networks. There is exactly one coordinator in each network. It is responsible for initiating the network and selecting the network parameters such as radio frequency channel, unique network identifier and setting other operational parameters. It can also store the information about network, security keys. Router acts as intermediate nodes, relaying data from other devices. Router can connect to an already existent network, also able to accept connections from other devices and be some kind of retransmitters to the network. Network may be extended through the use of ZIGBEE routers. End Device can be low-power /battery-powered devices. They can collect information from sensors and switches. They have sufficient functionality to talk to their parents (either the coordinator or a router) and cannot relay data from other devices. This reduced functionality allows for the potential to reduce their cost. They support better low power models. These devices do not have to stay awake the whole time, while the devices belonging to the other two categories have to. Each end device can have up to 240 end nodes which are separate applications sharing the same radio. The acknowledgement is generated from road side unit as soon as the road side unit receives the data from on board unit. This acknowledgement makes the on board unit to send only identity number towards road side unit to monitor traffic. This facility increases the efficiency of system. As the on board unit uses 8 bit microcontroller and ZIGBEE module the cost of on board unit is very low. 


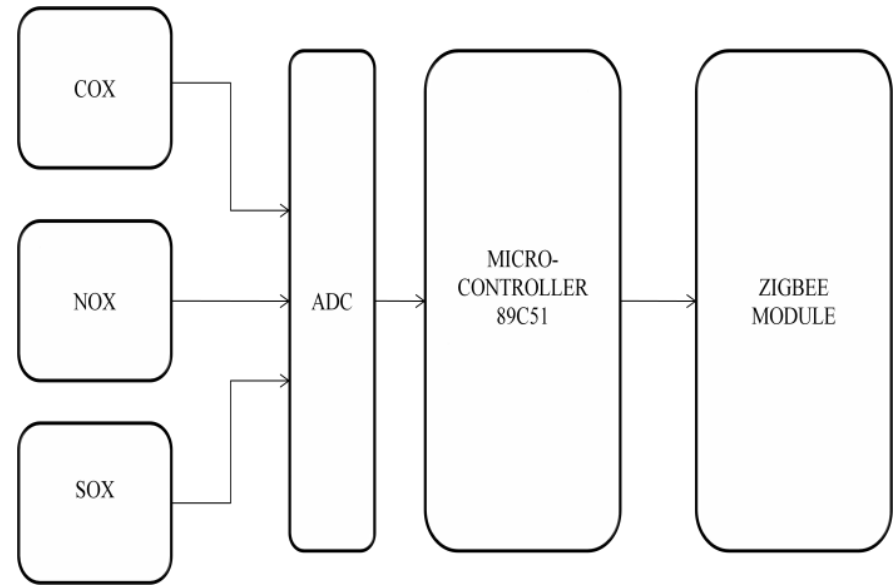

Fig-1: On board unit

Data flow in on board unit is given below,

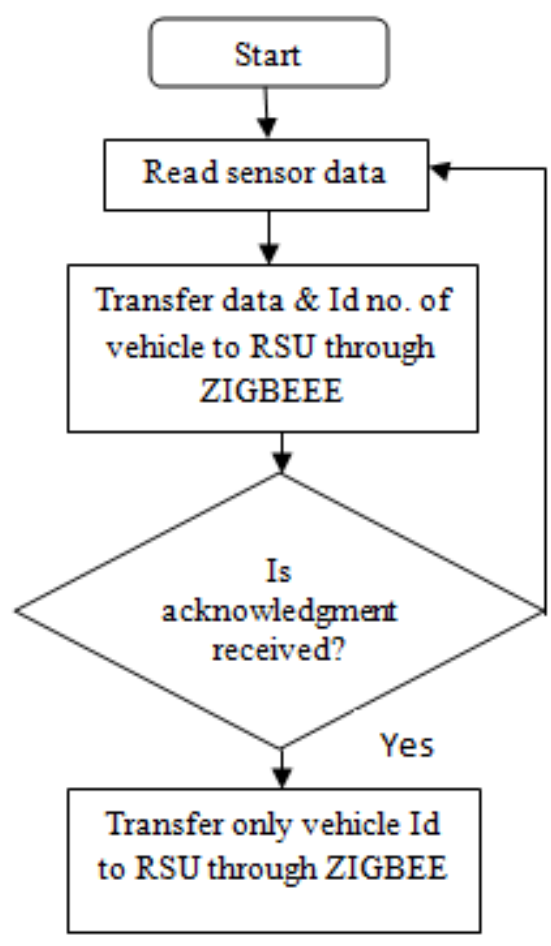

Fig-2: flow chat of on board unit

\subsection{Road Side Unit (RSU)}

Fig 3 shows road side unit the road side unit is mounted on the traffic signals. In this unit the ZIGBEE module receives data from on board unit which consist of information regarding pollution and identity number of vehicle. As soon as it receives data it will generate the acknowledgment toward vehicle of specific id. This data is fed to the Arduino module to send data on specific port with the help of GPRS shield. The ZIGBEE module helps to extend coverage area and gather all information in real time with low cost. The road side unit not only sends information of pollution through vehicles but also traffic threshold value at that junction. This information is used for traffic management purpose.

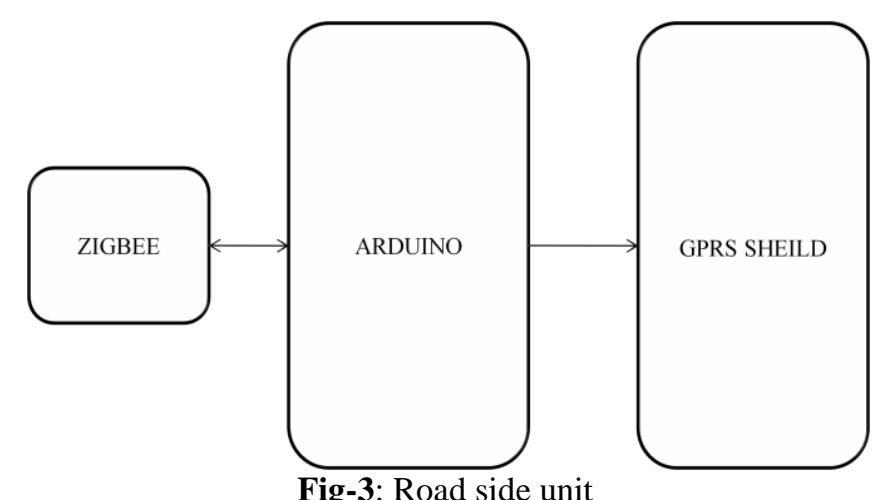

Fig-3: Road side unit

\subsection{Server Side Unit (SSU)}

Fig 4 shows Server side unit which consist of database at server. This database consists of data regarding pollution standards and vehicle owner identity. The data base is stored with the help of MY SQL. Server will compare original standard with data from vehicle. If pollution overcomes predefined value a message will generate in the favor of vehicle owner to convey him his vehicle not working properly.

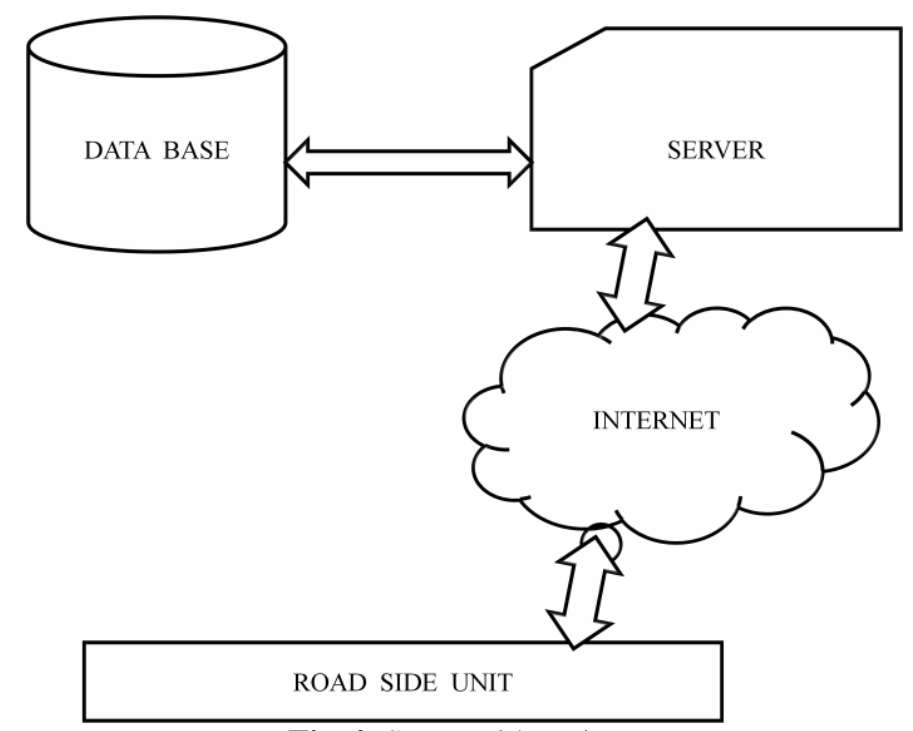

Fig-4: Server side unit

Traffic control system is a part of SSU used to control traffic flow according to traffic threshold value. Data flow in server side unit is given by, 


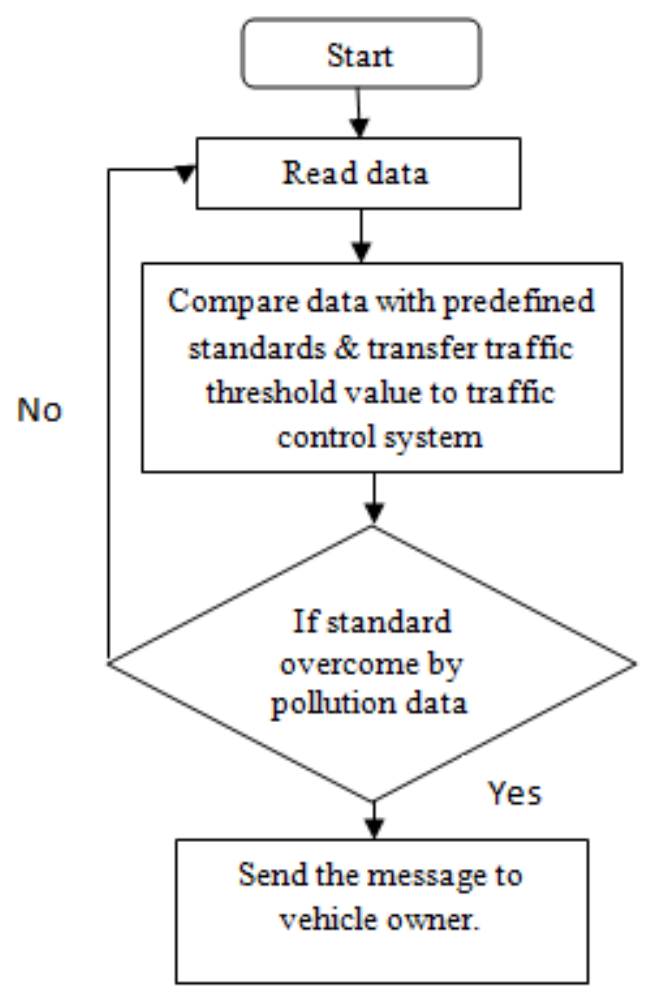

Fig-5: Flow chart of SSU

\section{TRAFFIC CONTROL}

\subsection{Traffic Threshold}

Vehicle traffic is a major problem in metro cities. The traffic can be monitored with the help of proposed system. at each signal road side unit is mounted. Each road side unit gives information regarding number of vehicles at that point. The threshold at each road side unit is calculated above which stand by time for vehicle is greater than the normal stand by time. Threshold formula given by

$$
¥=\alpha / \beta
$$

Where $¥$ - threshold value, $\alpha$ - number of vehicles present at road side unit, $\beta$ - pre defined number of vehicles.

If threshold is one or less than one then stand by time is normal stand by time and hence traffic at specific junction is normal. If threshold is greater than one number of vehicles are more and hence traffic. The value of threshold is calculated at each road side unit. This threshold value then transfer to server side unit vie GPRS shield.

\subsection{Traffic Signal Control}

At server side unit, once traffic threshold of road side unit is received then traffic signal is controlled according to value of traffic threshold. Various situations may occur at traffic signal. Some of them are addressed in this paper. Consider a traffic junction having threshold values A, B, C and D.
Case 1: when threshold value of $\mathrm{A}$ greater than one and other $\mathrm{B}, \mathrm{C}$ and $\mathrm{D}$ has value less than or equal to 0.25 then extend green phase time of signal having threshold value $A$ and reduce green phase time of $\mathrm{B}, \mathrm{C}, \mathrm{D}$.

Case 2: When A, B, C and D values are near to one with $20 \%$ tolerance. Then the signal green phase time should be same as predefined time.

Case 3: When value A, B is greater than 1 and value C, D is less than 0.5 then green phase time at point having threshold value $\mathrm{A}, \mathrm{B}$ is extended.

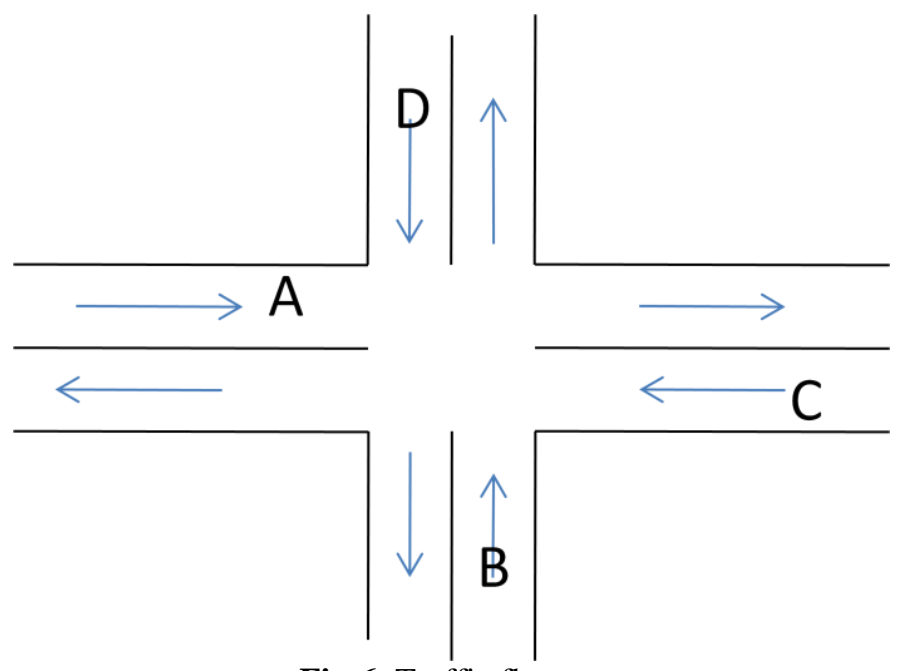

Fig-6: Traffic flow

\section{ADVANTAGES AND DISADVANTAGES}

\subsection{Advantage}

The main advantage of this system is reducing the cost of the system so vehicle owner will ready to mount the system on his vehicle. As the ZIGBEE is used for wireless communication between on board unit and road side unit so range problem is overcome through the system. Co2 emission occurred in vehicle more when vehicle tends to on at study position which maximum time occurred at signal so $\mathrm{Co} 2$ emission reduced by controlling traffic effectively. The problem of multi tagging is also solved in this system. Issues regarding security can be overcome as only id and pollution data has been sent.

\subsection{Disadvantage}

As the system requires database of vehicle owner so to implement the system willingness of government required.

\section{CONCLUSION}

This system is cost effective solution for vehicle emission problem and can be used for other application once it mounted on vehicle. By effectively managing traffic $\mathrm{co}_{2}$ reduction can be done also as the data regarding all vehicle owners is in server so it can be utilized for further application. A ZIGBEE tag is used to collect information regarding emission and then this information transferred to ZIGBEE receiver which is situated at the signal from where 
it sends information to server and then the values of emission compared and message sends to vehicle owner. The owner of vehicle has to repair the vehicle within next three message else next message of vehicle number will send to respected authority So the engine health conveyed to vehicle owner without taking his time.

\section{REFERENCES}

[1] www.epa.gov.

[2] Chi-Man Vong "Application of RFID Technology and the Maximum Spanning Tree Algorithm for Solving Vehicle Emissions in Cities on Internet of Things" 2014 IEEE World Forum on Internet of Things (WF-iot)

[3] Anita kulkarni1, T. Ravi Teja "Automated System for Air Pollution Detection and Control in Vehicles" /ijareeie.2014.0309061

[4] Chunxiao LI and Shigeru shimamoto "Etc assisted traffic light control scheme for reducing vehicles" International Journal of Managing Information Technology (IJMIT) Vol.4, No.2, May 2012.

[5] Areas Srinivas Devarakonda, Parveen Sevusu, Hongzhang Liu, Ruilin Liu, Liviu Iftode, Badri Nath "Real-time Air Quality Monitoring Through Mobile Sensing in Metropolitan"

[6] Darshana N. Tambe and Ms. Nikita Chavan "Detection of air pollutant using ZIGBEE" International Journal of Ad hoc, Sensor \& Ubiquitous Computing (IJASUC) Vol.4, No.4, August 2013

[7] A Distributed Algorithm for Spanning Trees R. G. Gallager, P. A. Humblet Massachusetts Institute of Technology.

[8] Akshay Kanwar, Aditi Khazanchi " ZIGBEE: The New Bluetooth Technology" International Journal Of Engineering And Computer Science ISSN:2319-7242 Volume1 Issue 2 Nov 2012 Page No. 67-74

[9] Nisha Ashok Somani 1 and Yask Patel 2 "ZIGBEE: a low power wireless technology for industrial applications" International Journal of Control Theory and Computer Modeling (IJCTCM) Vol.2, No.3, May 2012 DOI : 10.5121/ijctcm.2012.2303 27

[10] Kwang Soo Yoo" Gas Sensors for Monitoring Air Pollution" Department of Materials Science and Engineering, University of Seoul, Korea.

[11] www.wikipedia.com 